\title{
Effects of the Brazilian University Policy of Targeting the Poor
}

\author{
- Eduardo de Carvalho Andrade*
}

\begin{abstract}
RESUMO
Este trabalho analisa, teoricamente, os efeitos do Programa Universidade para Todos (ProUni), introduzido pelo governo federal do Brasil no ano de 2005, sobre a qualidade da força de trabalho formada nas universidades privadas. Esse programa concede isenção fiscal para as universidades privadas que, em contrapartida, fornecem bolsas de estudo para alunos provenientes de famílias de baixa renda. A análise sugere que a qualidade da força de trabalho pode aumentar ou diminuir dependendo de duas variáveis-chave: 0 formato da curva de oferta do setor universitário e o nível de preparação para cursar a universidade dos bolsistas vis-à-vis aos não-bolsistas.
\end{abstract}

\section{Palavras-CHAVE}

ProUni, universidade privada, ação afirmativa, eficiência

\section{ABstract}

This paper analyzes theoretically the effects on the quality of the labor force of the introduction of the program called ProUni (Programa Universidade para Todos), adopted by the Brazilian government in 2005. This program consists of giving tax exemptions to private universities that provide scholarships to students coming from low income families. The analysis suggests that the quality of the labor force can either increase or decrease depending on two crucial variables: the shape of the university sector's supply curve and the level of preparation to face university studies of the students who are targeted by the program vis-à-vis the non-targeted ones.

KEY WORDS

ProUni, private university, affirmative action, efficiency

\section{JEL Classification}

$\mathrm{HO}, \mathrm{H} 4 \mathrm{I}, \mathrm{I22}, \mathrm{I} 28$

+ I have benefited from comments and discussions with Paulo Barelli and Ernesto Sepúlveda and participants in seminar at the SBE Meeting in Natal in 2005 and the international conference on "The Quality of Education in Latin America and the Caribbean" in Mexico City in 2007 .Obviouly, all remaining errors are my sole responsability.

* Ibmec, São Paulo. Endereço para contato: Rua Quatá, 300 - $4^{\circ}$ andar. CEP: 04546-042 - São Paulo - SP - tel: II4504-2300. E-mail: eduardo.andrade@isp.edu.br.

Recebido em março de 2006. Aceito para publicação em fevereiro de 2007. 


\section{INTRODUCTION}

In 2005, the Brazilian government introduced a program called ProUni (Programa Universidade para Todos) to finance university tuition to low income families' students. The program has two main characteristics. ${ }^{1}$ First, private universities receive tax exemptions if they provide one full scholarship for each 10,7 students regularly registered. ${ }^{2,3}$ Participation in the program is voluntary. However, if private universities adhere to the program, the agreement lasts for ten years and it can be renewed. Second, the eligible students to receive the new scholarships are those who studied all three years in public high schools. ${ }^{4}$ Moreover, their families must have a monthly income no greater than one and a half and three minimum wages, respectively, to receive full and partial (50\% or 25\%) scholarships. ${ }^{5}$ As in Brazil the best elementary and high schools are in general private, these students tend to be, on average, relatively less prepared to face university studies. ${ }^{6}$ The students selected are those among the eligible ones who obtain the highest scores in the national exam called ENEM and are, as a last pre-requisite, selected by the private universities.

Out of 1652 private universities in the Brazilian educational system, 1135 adhered to the program, which corresponds to almost $70 \%$ of the total. As a result of this high participation, 112,000 slots with scholarships were directed to students coming from low income families. This number corresponds to close to $7 \%$ of all slots available to new students in all private universities in Brazil in 2003 whose selection were made through exam. ${ }^{7,8}$

The objective of this paper is to analyze theoretically the effects of this government's program on the quality of the labor force. The focus on the quality of the labor force is a very important one for two main reasons. On the one hand, it affects the economic growth rate and the economy's productivity. Hanushek and Kimko (2000) run a cross-country growth regression using data from 1960 to 1990 . They found

1 For details, see http://www.presidencia.gov.br/ccivil_03/_Ato2004-2006/2005/Lei/L11096.htm.

2 Universities that adhered to the program in 2005 had to provide only one full scholarship for each 9 regularly registered students.

3 To simplify, the term university also includes colleges and other institutions that provide tertiary education. With respect to the exemptions, they include reduction in corporate income tax and other contributions.

4 Students who studied in private high school with scholarships are also eligible to take part in the program.

5 The minimum wage in Brazil in 2005 is equal to R\$ 300 reais (or approximately US\$ 126, using the exchange rate of July 8th, 2005).

6 Families who can afford do send their children to private schools, even though they have the option of public education free of charge. The difference between the two types of school's quality is significant.

7 Only 9\% of all slots in all private universities in 2003 are filled with students selected through other forms rather than exam.

8 See MEC (2003) for further details about the higher education in Brazil. 
that an increase of one standard deviation of labor force quality, measured by the grades obtained by students on mathematic and science tests, may enhance the real per capita growth rate by approximately $1.4 \%$ per year. Bishop (1989) suggests that a drop in the american students' performance in the exam known as SAT, from 1967 to 1980, coincides with the decline in the american economy's productiviy. On the other hand, the quality of the labor force also affects the individuals. For example, Murphy and Peltzman (2004) suggest that a drop in one standard deviation of the students' performance in tests of proficiency leads to a reduction of $3 \%$ their average wage. This empirical evidence indicates the centrality of the nation's human capital and, in particular, its quality. ${ }^{9}$

With this aim to explore the effects of ProUni on the quality of the labor force, I develop a two-period model with two main features. First, the university sector is modelled explicitly, assuming that there is a continuum of private universities authorized by the government to function and they are price-takers. Second, there are two types of families. In families of the first type, parents have high level of human capital and can either send a child to university or not. If they do, there is a probability that a child who is sent to university becomes an individual with a high level of human capital, which depends positively on his or her level of preparation. In families of the second type, parents have low level of human capital and are credit constrained: they do not have enough resources to pay the university tuition. The government's program's target is clearly the latter type of families and its introduction can alter the allocation of human resources in the spots available in private universities, which affects the quality of the labor force.

The analysis in this paper suggests the following. As a result of the introduction of the program, the quality of the labor force can either increase or decrease depending on two crucial variables: the university sector's supply curve and the level of preparation to face university studies of the students who are the target of the program visà-vis the non-target ones. Independently of the former, if the level of preparation of the beneficiaries of the program are greater, the quality of the labor force necessarily rises. The explanation is the following. By providing scholarships to credit constrained families, the program's first effect is to increase the fraction of individuals who obtain the university degree. As a consequence, the skill premium reduces. Additionally, depending on the university sector's supply curve, the university tuition may increase. Combining these two effects, it makes not profitable for some families with high level of human capital to continue paying for a private education and obtain a lower immediate utility. Hence, they withdraw their children from university. As they are

9 This empirical evidence considers the effects on the quality of the labor in the pre-college period, as there are exams that allow an international comparison. However, one should also expect a significant impact (possibly lower) of the quality of college education, the focus of this investigation, on the same variables. 
replaced by better students (the scholarships' recipients), the quality of the labor force necessarily rises. Therefore, the program can increase efficiency and, at the same time, the income mobility.

However, the most likely scenario is one in which the level of preparation of the beneficiaries of the program is lower, as they come from public schools. Under this case, as more inelastic the university sector's supply curve, the greater is the increase in the university tuition, as a consequence of the higher demand in the university sector caused by the program. There is also a reduction in the skill premium, which is not very significant as the level of preparation of the scholarship's recipients are relatively low. Combining these two effects, a relatively large number of families with high level of human capital withdraw their children from university, who are now replaced by students with worse levels of preparation. As a consequence, the quality of the labor force is lower. Thus, the program increase the income mobility at the expense of less eficiency. There is a clear trade-off.

In contrast, as more elastic the supply curve, the quality of the labor force increases after the introduction of the program and no trade-off between efficiency and equity exists. It occurs because the university tuition does not change significantly. As the skill premium also does not change significantly, there are relatively few families with high level of human capital withdrawing their children from university. Combining this effect with a relatively greater number of scholarship's recipients entering the university, the final outcome is an increase in the fraction of individuals attending university and in the quality of the labor force. This result takes place despite the fact that the beneficiaries of the program are relatively less prepared to face university studies. One can say that that the quantity effect dominates.

Thus, how the university sector responds to the increase in demand is crucial to understand the impact of the program. The overall level of idle capacity in the Brazilian private university sector is around $20 \% .{ }^{10}$ However, this percentage is possibly not homogenous across different courses, which suggests that the effects of the program may also vary across courses. Moreover, government's legislation that restricts the opening either of new universities or new slots in universities may play an important role in the program's outcome, which I discuss in the final section of this paper.

To my knowledge, this is the first paper that analyzes the recently implemented ProUni. It adapts a theoretical framework developed by Caucutt and Kumar (2003), which analyzes the effects of increasing higher education subsidies in the US on inequality, welfare, and efficiency. Andrade (2004) uses a different version of this

10 The idle capacity number in the higher sector should be looked at with caution. The Ministry of Education is responsible for authorizing new places in most of the universities. As this process may take a long time, many universities demand new slots even if they do not plan to use them immediately. 
paper in which the goal was to investigate theoretically the impact on efficiency of the introduction of quotas into the Brazilian public universities' entrance system.

The rest of this paper is organized as follows. The next section presents the structure of the model. Section 2 shows the competitive equilibrium without the government's program. In section 3 , the effects of the introduction of the program on the quality of the labor force are analyzed. The last section concludes, with special emphasis on the discussion about the level of idle capacity in the university sector in Brazil now and in the near future, as this variable is key to understand the effect of the program.

\section{MODEL}

It is a two-period model. There are two types of families, which differ by the parent's level of human capital. At time $t=0$, parent has either a high or a low level of human capital. Each parent works, receives wages, decides whether to send his child to university, consumes, and dies. At time $t=1$, his child becomes a worker with high or low level of human capital, depending on the educational decision of his parent, receives a wage, and consumes. ${ }^{11}$ The measure of each generation (and the number of workers in each period) is constant and is normalized to one. Let $n_{h, t}$ and $n_{l, t}$ be the fraction of individuals, respectively, with high and low levels of human capital at time $t$. Note that $n_{h, 0}=n_{h, 0}^{*}$ and $n_{l, 0}=n_{l, 0}^{*}$ are exogenously given, and $n_{h, 0}^{*}+n_{l, 0}^{*}=1$.

As I do not model the schooling decision, it is assumed that all children have a school degree and are able to attend university. However, they differ in their level of preparation to perform well at university and become an individual with a high level of human capital. A child with level of preparation $a$ who attends university becomes an individual with high or low level of human capital, respectively, with probability $\pi(a)$ and $(1-\pi(a))$. This feature of the model limits the heterogeneity to two levels of human capital, and therefore to two income levels, which simplifies the analysis. If a child does not attend university, he has the lower level of human capital with probability one.

I assume that the distribution function for the level of preparation is different across types and identical within families of the same type, and all level of preparation draws are independent of each other. Let $F($.) be the distribution function for the high income families' level of preparation on the support $\left[\underline{a}_{h}, \mathrm{l}\right]$, and $f($.$) be the corresponding$ density function. Let $G($.) be the distribution function for the low income families'

11 As it is going to become clear in the next section, the low type individual ends up not sending their child to university as he is credit constrained. 
level of preparation on the support $\left[0, \bar{a}_{l}\right]$, and $g($.$) be the corresponding density func-$ tion. Note that $0<\bar{a}_{l},<\underline{a}_{h} \mathrm{l}$.

Assumption 1: $a \in[0,1], 0 \leq \pi(a) \leq 1, \pi^{\prime}(a)>0, \pi^{\prime \prime}(a)<0, \forall a$, and $\pi\left(\underline{a}_{h}\right)=0$.

This feature of the model is motivated by the following. The level of preparation of an individual to attend university and acquire a high level of human capital is determined in great part by two factors. The first is the individual's innate or cognitive ability, which is independent of the social environment where the individual grows up. There is no reason to assume that the distribution of this innate ability differ between groups of individuals who differ by family income status. ${ }^{12}$ The second factor is related to expenditures in education received by the individual before entering university. This second factor is greatly affected by the income of the individual's family. For example, high-income families are capable of paying for extra courses and better quality schools. ${ }^{13}$ This is particularly true in Brazil as high income families are able to afford private schools, which are in general better than public schools. Combining these two factors, it is set $\bar{a}_{l}<1$ and $0<\underline{a}_{h}$.

The parent whose child has level of preparation $a$ has two options: sending the child to attend university or college (option $c$ ) or letting the child remain solely with a school degree (option $s$ ). Hence, the family's problem can be written in the following way:

$$
\begin{aligned}
& \max _{\{c, s\}}\left\{u\left(w_{i, 0}-P^{*}+T_{i}(a)\right)+\beta\left[\pi(a) u\left(w_{h, 1}\right)+(1-\pi(a)) u\left(w_{l, 1}\right)\right]\right. \\
& \left.u\left(w_{i, 0}\right)+\beta u\left(w_{l, 1}\right)\right\}, i=h, l
\end{aligned}
$$

where $\beta(0<\beta<1)$ is the discount factor, $w_{i, t}$ is the wage of individual with $i$ level of human capital at time $t, P^{*}$ is the university tuition, $T_{i}(a)$ is government's transfer to family $i$ with child's level of preparation equal to $a$ and the utility function has the usual properties. ${ }^{14}$ The first term indicates the university option. At $t=0$, the family consumes its wage net of the tuition expenditures and sends its child to university. At $t=1$, the child who becomes a worker either with high or low level of human capital earns his wage. The second term is the option of not sending the child to university at all: the child becomes a worker with low level of human capital. ${ }^{15,16}$

12 See Heckman (1995).

13 See discussion in Becker (1993).

14 Below in this section, I explain which families receive transfers.

15 To simplify the analysis, the tuition $P^{*}$ is the only cost of higher education. This paper ignores the opportunity cost of foregone earnings, an important component of the cost of education, and assume that the child who do not attend university can not work at time $t=0$.

16 It is worth mentioning that parents' income is not necessarily equal to their consumption as part of its income may be directed to invest in their children's human capital. However, children's consumption is equal to their income at $t=1$. 
Two comments are worth noting before proceeding to describe production in this economy. First, the only type of bequest allowed in this model is through investments in education. Other types of bequests are not empirically relevant for most families, even in the most developed countries. ${ }^{17}$ Second, there is no capital market to finance education. This assumption is commonly used and widely accepted. ${ }^{18}$ In general, there are two types of uncertainties associated with investments in human capital. On the one hand, it is not clear if the student is capable of finishing his studies. This type of uncertainty is somehow modelled here through the probability $\pi$. On the other hand, after graduating, there is a moral hazard problem. The individual may not work properly or be a lazy person. As a consequence, he may not earn enough money to repay his debts. Although this possibility is not modelled here, it is implicitly incorportated by assuming the lack of a market to finance investiments in education.

As in Andrade (2004), there is a single non-storable good in the economy produced by firms operating in a competitive market. The inputs in the production process are the two types of labor, individuals with high and low levels of human capital. Therefore, there is no physical capital in this economy. The constant returns to scale production function is as follows:

$$
Y_{t}=A\left[\theta\left(N_{h, t}+\gamma N_{l, t}\right)^{d}+(1-\theta)\left(N_{l, t}+\varepsilon N_{h, t}\right)^{d}\right]^{\frac{1}{d}}
$$

where $A>0,0<\theta, \varepsilon, d, \gamma<1, \gamma<\varepsilon . N_{h, t}$ and $N_{l, t}$ are, respectively, the number of individuals with high and low levels of human capital employed in the production process at time $t$. Note that the possible values for the variables $N_{l, t}$ and $N_{h, t}$ are in the interval $[0,1]$, as the number of workers in each period is constant and is normalized to one. Hence, total output can be expressed as a function of the fraction of individuals with a high level of human capital in each period.

Both types of individuals provide two distinct productive services, which one may think of as mental effort ("brains") and physical effort ("brawn"). ${ }^{19}$ The first and second terms within the square brackets can be thought of, respectively, as "brain" and "brawn", with the parameter $\theta$ indicating the importance of the mental effort. Thus, mental and physical efforts are combined into an aggregate by a CES technology with an elasticity of substitution, $\frac{1}{1-d}$, that exceeds unity. The parameter $\varepsilon$ is the relative efficiency of the individuals with high level of human capital in supplying physical effort. Whereas the parameter $\gamma$ is the relative efficiency of the individuals with low

17 See Stokey (1998) for an extensive discussion of this topic.

18 See Becker (1991) for an extensive discussion of this topic and Caucutt and Kumar (2003).

19 This type of production function is used in Stokey (1996), Caucutt and Kumar (2003) and Andrade (2004). 
level of human capital in providing the mental effort. Both parameters $(\varepsilon$ and $\gamma)$ are important in determining the wage differential between the individuals with high and low level of human capital, as assumption 2 below indicates.

There are two important ideas behind this production function. First, as $\gamma$ is assumed to be close to zero, the individuals with high level of human capital are the main providers of "brain". Second, as $\varepsilon<1$, the individuals with a high level of human capital can perform (almost) all the tasks that the other type of labor can, and more. The following assumption simplifies the analysis and guarantees that the wages paid to the individuals with a high level of human capital are always greater than the ones for the individuals with a low level of human capital, for all possible values for $N_{h, t}$ and $N_{l, t}$.

Assumption 2: $\varepsilon>\left(\frac{1-\theta}{(1-\gamma) \theta}\right)^{\frac{1}{1-d}} \cdot 20$

I now turn to the market for higher education. It is assumed that there is no free-entry and there is a continuum of universities with measure $U$. The maximum number of students that each university can have is equal to $Q^{\max }$ (that is, the maximum capacity). University $i$ 's profit $\left(P R_{i}\right)$ is given by:

$$
P R_{i}=\left[P^{*} Q_{i}-C_{i} Q_{i}\right](1-t)
$$

where $t$ is the corporate income tax, $C_{i}$ is university $i$ 's marginal cost, $Q_{i}$ is the number of students enrolled in university $i$ and $P^{*}$ is the market price. Universities have different marginal costs and its range is given by the interval $\left[C^{\min }, C^{\max }\right]$. Recall that there is a continuum of universities with measure $U$. The universities are labeled according with its marginal cost: from the one with the lowest marginal cost labeled $i=0$ to the one with the highest marginal cost labeled $i=U$.

These features of the model try to capture the main characteristics of the Brazilian education sector. This market is strongly regulated by the government. There is no free-entry as the government determines the number of of universities that can operate in each field of knowledge. Moreover, it specifies the number of slots that the university can have, that is, the maximum number of students that can be enrolled in each university.

20 This assumption indicates that $\varepsilon$ (the coefficient of the individual with a high level of human capital in the production of "brawn") is large enough to guarantee that $w_{h, t}>w_{l, t}$. 
The government's budget constraint has to be balanced. The revenue comes from the corporate income taxes on the universities imposed at $t=0$. Government makes transfer denoted by $T$. Therefore:

$$
\int_{i}\left[P^{*} Q_{i}-C_{i} Q_{i}\right] t d i=T
$$

The last feature of the model is the following. I make the simplifying assumption that high income families whose children have the highest level of preparation (that is, $a=1$ ) receive all transfers from the government and all profits as they are assumed to own all universities.

The motivation behing this assumption is the following. Note that these families are the richest with the brightest children. As next section shows, it certainly pays off for these families to finance their children's tertiary education. The extra cash through transfers and profits does not affect their decision to invest in their children's education. They would make this decision anyway if their income was only their salaries. The only effect of this extra cash is to increase their consumption in the first period. As section 3 shows, the government's university policy of targeting the poor affects the amount of transfers and profits. If they were channeled to families with lower income or with children with lower level of preparation, the amount of transfers and profits could distort and affect their decisions to send or not their children to university. In order to avoid this possibility, I make this simplifying assumption.

\section{COMPETITIVE EQUILIBRIUM}

This section discusses the equilibrium of the model. First, it is important to recall that the focus of this paper is to analyze the effect of the government program of targeting poor families whose children are not enrolled in university. Hence, the type of equilibrium of interest is the one in which all low income families opt not to send their children to university. It can happen for two reasons. Either because they do not have enough income to pay the tuition (that is, $w_{l, 0}<P^{*}$ ) and can not borrow with this objective as there is no capital markets to finance education.; or because the potential increase in future utility if the child becomes an individual with high level of human capital does not compensate the reduction in current utility related to the payment of tuition $P^{*}$. To simplify, I make the following assumption:

Assumption 3: $w_{l, 0}<C^{\min }$ and $w_{h, 0}>C^{\max }$. 
In words, it indicates that low income families do not have income to pay the university tuition. Their income is lower than the lowest possible university tuition, as the minimum possible marginal cost to provide the university service is $C^{\min }$. High income families do have enough income to pay tuition.

It is worth characterizing the behavior of parents with high level of human capital with respect to the decision to send their child to university.

Proposition 1: Given the equilibrium wages and university tuition, there exists an unique $a_{h}{ }^{*}\left[a_{h}, 1\right]$, such that a parent with high level of human capital sends his child to university if $a \geq a_{h}^{*}$, and does not otherwise. ${ }^{21}$

This proposition indicates that there is threshold level of ability behavior. Parents with high level of human capital send their children to university only if their children's level of preparation is greater than the threshold values $a_{h}{ }^{*}$. If a child has a level of preparation lower than this threshold value, it is not profitable to pay for private education and obtain a lower immediate utility. This is the case because the expected future gain in utility, as a result of the expenditure $P^{*}$ in education today, is very small, as the probability of this child becoming an individual with a high level of human capital is very low.

Before proceeding to define the competitive equilibrium in this economy, it is worth discussing the equilibrium in the university sector, which is characterized by a competitive market. From the behavior of parents with high level of human capital, there is a certain number of students who attend university, say, $D$. There are two possible types of equilibrium. In the first one, there is no idle capacity in the university sector. Formally, $D=U Q^{*}$, that is, the number of students enrolled in universities are equal to the number of slots available, the ones authorized by the government to operate. Hence, all universities are operating at full capacity and the equilibrium price is equal to $P^{*}=C^{\max }$, as the least efficient universities (with the highest marginal cost given by $C^{\max }$ ) equate the marginal cost to price. In such environment, when the demand increases, it leads to a greater equilibrium price without any increase in the number of students enrolled in universities. In the second possible equilibrium, there is idle capacity in the university sector as $D<U Q^{*}$. It means that the least efficient universities have the authorization to operate but there is no demand to fill their slots. The equilibrium price is such that $C^{\min } \leq P^{*}<C^{\max }$, as the least efficient universities with students equate their marginal cost (which is in the interval $\left[C^{\min }, C^{\max }\right)$ ) to the equilibrium price. Under this circumstance, an increase in demand may lead to greater price and necessarily increases the number of university students.

21 See in the appendix the proof of all propositions in this paper. 
In short, it is straightforward to conclude that, in equilibrium, there is a threshold $C^{*}$ such that universities with marginal cost: (i) greater than $C^{*}$ do not have students; (ii) lower than $C^{*}$ operate at full capacity; (iii) equal to $C^{*}$ have students but do not necessarily operate at full capacity.

I now turn to the definition and the proof of existence and uniqueness of the equilibrium.

Definition 1: Given $n_{i, 0}^{*}$, a competitive equilibrium is characterized by $n_{i, 1}^{*}, w_{i, 0}^{*}, w_{i, 1}^{*}, P^{*}$ and $a_{h}^{*} \in\left(a_{h}, 1\right)$ such that $(i=h, l)$ : (i) given wages, firms maximize profits; (ii) given $P^{*}$, universities maximize profits; (iii) the labor market clears, that is, $N_{h, t}=n_{h, t}^{*}$ and $N_{l, t}=n_{l, t}^{*}$ $(t=0,1)$; (iv) given wages and $P^{*}, a_{h}^{*}$ solves the university decision problem of family with high level of human capital in (I); ( $v(v)$ the government budget constraint is balanced; and (vi) the law of motion for the variable $n_{h}$, which is given by:

$$
n_{h, 1}^{*}=n_{h, 0}^{*} \int_{a_{h}^{*}}^{1} \pi(a) f(a) d a
$$

In order to understand the above law of motion, it is important to recall the following points. First, children from low income families do not attend university. Second, the number of individuals with high level of human capital at $t=0$ is equal to $n_{h, 0}^{*}$ and each one has a child. Third, their children who attend the university are only those whose level of preparation is in the the interval $\left[a_{h}^{*}, 1\right]$. Finally, only a fraction of those students becomes an individual with high level of human capital at time $t=1$, which is determined by the probability function $\pi$. Therefore, at $t=1$, the number of individuals with high level of human capital is a fraction given by $\int_{a_{h}^{*}}^{1} \pi(a) f(a) d a$ of the current ones $\left(n_{h, 0}^{*}\right)$.

Proposition 2: There exists a competitive equilibrium and it is unique. ${ }^{22}$

This unique equilibrium has the following characteristics. First, there are children coming from high income families who attend university. Second, the skill premium and the fraction of individuals with a high level of human capital at $t=1$ are positive. Finally, a threshold marginal cost such that universities with higher costs do not have students and the ones with lower costs operate at full capacity.

22 If one takes into consideration the opportunity cost of foregone earnings as an additional cost of higher education, the equilibrium would still be characterized by threshold ability. However, it would be greater as it would be an additional cost of attending university. 


\section{TARGETING THE POOR}

In this section, I analyze the effect of ProUni in the quality of the labor force. In the model, this quality is measured by the fraction of individuals with high level of human capital in period 1 , the variable $n_{h, 1}$. The goal is to check how $n_{h, 1}$ is affected, when one considers the possible changes in the equilibrium price in the university sector as a result of a greater demand caused by the introduction of the government program.

As mentioned in the introduction, ProUni's objective is to find a way to finance the private university tuition for students coming from low income families. The program has two important characteristics. First, only students whose families have an income level below a certain threshold are eligible to take part in the program. Those students take an exam and the ones with the highest scores obtain the scholarship. Second, it gives tax exemption to universities that give a certain minimum of full or partial scholarships to students enrolled in their program.

The way that these two characteristics are incorporated into the model is the following. With respect to the first characteristic, families whose parents have the low level of human capital and an income of $w_{l, 0}$ are the ones eligible to take part in the program. In other words, it is assumed that $w_{l, 0}$ is lower than the income threshold level established in the program. Moreover, the students with the right to receive the scholarship are selected using a ranking of the individual's level of preparation, which is assumed to be public information. They are the $S$ individuals with the highest level of preparation among the ones coming from low income families, where $S$ is the total number of scholarships. Implicitly, it is assumed that these individuals are the ones who obtain the highest scores in the exam that selects the students to receive the scholarships. Formally, the $S$ indiviuals are the following:

$$
S=\int_{a_{l}^{*}}^{\bar{a}_{l}} g(a) d a
$$

where $a_{l}{ }^{*}$ is the lowest level of preparation of those individuals coming from low income families who receive the scholarship.

With respect to the second characteristic of the program, I assume that the minimum number of full or partial scholarships an university has to offer to obtain the tax exemption and take part in the program is equal to $\alpha Q^{\max }$, where $\alpha<1$. When operating at full capacity, university $i$ 's profit if it decides to take part in the program is equal to: 


$$
P R_{i}=\left[P^{* *}(1-\alpha) Q^{\max }-C_{i} Q^{\max }\right](1-t)+F
$$

where $F$ is the tax exemption, $P^{* *}$ is the new equilibrium price when the program is implemented. Obviously, this university decides to join the program only if it leads to a greater profit. Formally, this is the case when:

$$
F \geq P^{* *} \alpha Q^{\max }(1-t)
$$

that is, when total exemption is greater than the amount the university gives up in terms of net revenues by providing scholarships.

It is obvious that if an university operating at full capacity is better off taking part in the program, then all universities join the program. To simplify the analysis, I assume that inequality (3) holds. ${ }^{23}$ With this assumption, total number of scholarships $(S)$ is equal to $\alpha Q^{\max } U$. It is important to note that this simplifying assumption does not play any role in the results below. As it is going to be clear, one of the crucial aspects to evaluate how the program affects the quality of the labor force is through its impact on the university tuition $\left(P^{*}\right)$, which depends on the supply curve of the educational sector and not on what types of universities take part in the program. ${ }^{24}$

Before proceeding with the analysis, it is worth making on comment about the way the production in the education sector is modelled here. Obviously, the fixed cost is an important aspect of the production in this sector. However, those universities who can take part in ProUni are those who are already operating and have their full capacity determined by the government. Therefore, their decisions to join or not the program are made at the margin. This point explains the focus on the marginal cost in the analysis. ${ }^{25}$

I now turn to the effects of the program in $n_{h, 1}$, first considering the case when the supply curve in the university sector is perfectly inelastic.

Proposition 3: After the introduction of the program, if the university sector's supply curve is perfectly inelastic and the level of preparation of targeted students vis-à-vis the non-targeted ones is greater (lower), the quality of the labor force increases (decreases).

23 As pointed out in the introduction, about $70 \%$ of all private universities adhered to the program. Therefore, this assumption is not really far from reality.

24 In order to guarantee that the government has enough resources to finance the program such that the condition (3) holds, adjustments can be made in the corporate income tax $(t)$ or in the number of scholarships through $\alpha$.

25 In propositions and below, the university sector's supply curve can be, respectively, perfectly elastic and upward sloping. Therefore, implicitly it is assumed that new universities can enter into the market or old universities can increase their full capacity as a consequence of the initial impact of ProUni. 
The intuition behind this result is the following. When the program is introduced, there is an increase in demand in the university sector. As the supply curve is perfectly inelastic, it leads only to an increase in the university tuition, without any change in the total number of students enrolled in university. This new equilibrium price is such that it is not in the interest of $\alpha Q^{\max } U$ students with the lowest level of preparation coming from high income families who were attending university without the program to continue doing so. Their families decide to withdraw their children from university as it is not profitable to pay the higher tuition for an university education and obtain a lower immediate utility. In other words, with the new equilibrium price, the costs are now greater than the benefits of enrolling in the university.

These studentes are then replaced by the $\alpha Q^{\max } U$ recipients of the scholarships, the students coming from low income families who are eligible to take part in the government's program. When $a_{h}^{*}<a_{l}^{*}$, the level of preparation of these new students are greater than the ones of the old students. They were not previously enrolled in university because they were credit constrainted $\left(w_{0,1}<P^{*}<P^{* *}\right)$. Thus, the government's program is capable of increasing the quality of the students enrolled in universities, leading to a greater quality in the labor force in the future (greater $\left.n_{h, 1}\right)$. As a second order effect, this increase in $n_{h, 1}$ reduces the expected skill premium in the future and high income families are less inclined to send their children to university. When this effect is taken into consideration, the new equilibrium price of university service and the new fraction of individuals with high level of human capital at time $t=1$ are lower than otherwise. However, they are still greater than the ones without the government program. In this case (when $a_{h}^{*}<a_{l}^{*}$ ), it is important to mention that there is no trade-off in terms of efficiency and income mobility. The government's intervention not only increases the efficiency of the educational system (by increasing $\left.n_{h, 1}\right)$, but it allows individuals coming from low income families to obtain a high level of human capital. Moreover, the skill premium is lower.

The reverse result occurs when $a_{h}^{*}>\bar{a}_{l}$ as the new students have lower level of preparation. In this case, the overall quality of the labor force $\left(n_{h, 1}\right)$ decreases after the introduction of the program. Under this scenario, the government would spend resources through tax exemptions and reduce the efficiency of the educational system. There is now a clear trade-off between efficiency and income mobility: more income mobility is only possible at the cost of less efficiency.

Proposition 4: After the introduction of the program, if the university sector's supply curve is perfectly elastic, the quality of the labor force increases.

The above result is a straightforward one and it is considered for the sake of completeness. The explanation is the following. When the supply curve is perfectly elas- 
tic, there is enough idle capacity in the university sector and the introduction of the government's program does not cause any change in the university tuition. Hence, in the first moment, the old students' families do not have any incentive to change their decisions to send their children to university. As a result, there are new $\alpha Q^{\max } U$ university students and they receive scholarships. Recall that these students are the ones coming from low income families who do not have enough income to pay for the tuition. Therefore, the quality in the labor force in the future (measured by $n_{h, 1}$ ) is necessarily greater. Note that this result does not depend on the level of the preparation of the new student vis-à-vis the other students as there is no replacement of students when there is idle capacity in the system. As a second order effect, this increase in $n_{h, 1}$ reduces the expected skill premium in the future and high income families are less inclined to send their children to university. When this effect is taken into consideration, the new fraction of individuals with high level of human capital at time $t=1$ are lower than otherwise. But it is still greater than this same fraction without the program. In the case of perfectly elastic supply curve, the effect of the program is unequivocal: more efficiency and income mobility, with a lower skill premium.

Proposition 5: After the introduction of the program, if the university sector's supply curve is upward sloping and the level of preparation of targeted students vis-à-vis the non-targeted ones is greater (lower), the effect on the quality of the labor force is positive (uncertain).

The above propostion presents the intermediary case when the supply curve is neither perfectly inelastic nor perfectly elastic, but it is positively inclined. The results are thus a combination of the previous ones. Recall that, in this case, when demand increases due to the program's implementation, price and quantity rise.

As seen above, when $a_{h}{ }^{*}<a_{l}{ }^{*}$, there is an increase in $n_{h, 1}$ even when the increase in demand affects solely the equilibrium price (the perfectly inelastic case). When this effect is distributed in price and quantity, it is straightforward to conclude that $n_{h, 1}$ necessarily rises too.

When $a_{h}{ }^{*}>a_{l}$, it is uncertain what is the effect of the introduction of the program on $n_{h, 1}$. From the previous results, we learned two facts: first, in the perfectly inelastic case, only price increases (no quantity change) and $n_{h, 1}$ reduces; second, in the perfectly elastic case, only quantity increases (no price change) and $n_{h, 1}$ rises. In the upward sloping case, price and quantity increase. Thus, as more inelastic the supply curve, greater is the increase in price vis-à-vis the quantity, and it is more likely to occur a decrease in $n_{h, 1}$. In other words, the price effect dominates. Whereas, the more elastic the supply curve, the reverse occurs and the quantity effect overrules. 


\section{CONCLUSION}

In 2005, the Brazilian government launched ProUni, a program to finance university tuition to credit constrained families. Private universities provide scholarships to the target group defined by the government and receive tax exemptions in return. As the analysis above shows, the effect of this program on the quality of the labor force is ambigous. The result depends on two key variables: the university sector's supply curve and the level of preparation to face university studies of the students who are targeted by the program vis-à-vis the non-targeted ones.

When the program is introduced, there is an increase in demand in the university sector. Depending on the supply curve, three possibilities can occur. First, university tuition rises and total number of university students does not change, when the supply curve is perfectly inelastic. Second, price does not change and quantity increases, when the supply curve is perfectly elastic. Finally, price and quantity increase, when the supply curve has an upward slope.

Non-target families are penalized when the university tuition rises. Some of them may decide to withdraw their children from university. If their levels of preparation are lower than the ones of the children from the target families who received the scholarships, then the program is capable of increasing the quality of the labor force by eliminating the credit constraint of better qualified students.

However, it is more likely that the level of preparation of the individuals from the target group be lower. In this case, the more inelastic the supply curve, greater is the increase in tuition after the program's introduction and more individuals from the non-target group do not go to university. As they are replaced by individuals from the target group who are less prepared students, the quality of the labor force drops.

The current situation in the university sector, with an idle capacity in general around $20 \%$, may suggest that university tuition may not increase significantly after the program. However, it is possible that the level of capacity utilization may vary from course to course and, as a result, the effects of the program on the quality of the labor force may also vary across them. It would be interesting to check empirically if there are important changes, in the future, in the quality of those professionals graduating from courses operating close to full capacity today vis-à-vis the others. Moreover, one could argue that tuition could decrease without the program exactly because the idle capacity and benefit at the margin individuals better qualified to pursue university studies than individuals from the target group. 
As pointed out in the introduction, $70 \%$ of all private universities joined the program and they have to stay in the program for at least ten years. It is true that the model in this paper is a static two-period model. Nevertheless, it is possible to use it to make some speculations about the effects of the program in the near future.

Even if there is today, in general, idle capacity in the university sector, one could argue that this reality may change in the future. On the demand side, there has been an important increase in the number of students graduating from high school that is expected to continue. On the supply side, it is expected to have some important limitations. On the one hand, the government has important budget limitations and is not likely to be able to expand the number of slots available in the public universities. On the other hand, the current government has maintained a very strict policy regarding the authorization for new universities to start operating and old ones to augment their operating size. Two examples illustrate this policy. In 2004, the Ministry of Education suspended for 180 days any authorization to create new courses. In 2005, in the project to reform the university sector, the same Ministry of Education suggested the transfer from the government to professional associations of the legal right to authorize the openings of new courses in some areas, such as in medicine. These associations tend to limit severely the number of new professionals (and slots in universities) in order to guarantee to their members a certain degree of monopoly. ${ }^{26}$ Combining the demand and supply sides, the "no idle capacity" case, in which the quality of the labor force declines as a result of the government's program, may occur in the future.

It is important to make one final comment. The analysis in this paper focus solely on the impact of the program on the quality of the labor force. It concludes that it is not unlikely that its impact is negative. If a more complete analysis is implemented it is possible that one can find that its additional impacts can be even more negative. In particular, if one takes into consideration the costs and the benefits of the alternative uses of the funds employed to finance the program. Therefore, a more complete analysis should be implemented in future research and its overall effect on economic welfare considered.

\section{REFERENCES}

Andrade, E. Quotas in Brazilian public universities: good or bad idea? Revista Brasileira de Economia, v. 58, n. 4, p. 453-484, 2004.

Becker, G. A treatise on the family. Harvard University Press, enlarged edition, 1991.

26 For a good discussion on this topic, see Friedman (2002). 
. Human capital: a theoretical and empirical analysis, with special reference to education. The University of Chicago Press, 1993.

Bishop, J. Achievement, test score, and relative wage. In: Workers and their wages. Washington, DC: The AEI Press, 1991.

Caucutt, E.; Kumar, K. Higher education subsidies and heterogeneity: a dynamic analysis. Journal of Economic Dynamic \& Control, 27, p. 1459-1502, 2003.

Friedman, M. Capitalism and freedom. The University of Chicago Press, 2002.

Hanushek, E.; Kimko, D. Schooling, labor-force quality, and the growth of nations. The American Economic Review, December 2000.

Heckman, J. Lessons from the bell curve. Journal of Political Economy, v. 103, n. 5, p. 1091-1120, 1995.

MEC. Censo da Educação Superior. Disponível em: http://www.inep.gov.br/superior/ censosuperior/, 2003

Murphy, K.; Peltzman, S. School performance and the youth labor market. Journal of Labor Economics, v. 22, n. 2, 2004.

Stokey, N. Free trade, factor returns, and factor accumulation. Journal of Economic Growth, v. 1, n. 4, p. 421-47, 1996.

Shirtsleeves to shirtsleeves: the economics of social mobility. In: Frontiers of research in economic theory: The Nancy L. Schwartz Memorial Lectures, 19831997, p. 210-41. Cambridge University Press, 1998.

APPENDIX

Proposition 1: Given the equilibrium wages and university tuition, there exists an unique $a_{h}^{*} \in\left(\underline{a}_{h}, 1\right]$, such that a parent with high level of human capital sends his child to university if $a \geq a_{h}^{*}$, and does not otherwise.

Proof: Given the equilibrium wages and university tuition and using assumption 3, the utility of the family with high level of human capital with and without sending his child to university are, respectively, equal to:

$$
\operatorname{LHS}(a)=u\left(w_{h, 0}^{*}-P^{*}\right)+\beta\left[\pi(a) u\left(w_{h, 1}^{*}\right)+(1-\pi(a)) u\left(w_{l, 1}^{*}\right)\right]
$$

and

$$
R H S=u\left(w_{h, 0}^{*}\right)+\beta u\left(w_{l, 1}^{*}\right)
$$


Note that RHS does not depend on $a$.

Using the facts that $\pi\left(\underline{a}_{h}\right)=0$ from assumption $\mathrm{l}$ and $u^{\prime}>0$, one obtains that for any possible value for $w_{l, 1}{ }^{*}$ the following:

$$
\operatorname{LHS}\left(\underline{a}_{h}\right)<R H S
$$

Using the fact that $\pi^{\prime}(a)>0$ from assumption $1, \operatorname{LHS}(a)$ is strictly increasing in $a$. Hence, the LHS and the RHS either intersect at a unique $a_{h}{ }^{*}>\underline{a}_{h}$, or do not intersect at all, in which case $a_{h}^{*}=1>\underline{a}_{h}$.

Proposition 2: There exists a competitive equilibrium and it is unique.

Proof. Proof. The equilibrium is characterized by seven unknowns $\left(w_{h, t}^{*}, w_{l, t}^{*}, n_{h, 1}^{*}\right.$, $a_{h}^{*}, P^{*} ; t=1,2$ ) and seven equations (the four first-order conditions of the firm's problem (two in each period), the equilibrium condition in the university sector, the law of motion for the variable $n_{h, t}$ and the threshold ability for individuals with high level of human capital).

Given $n_{i, 0}^{*}$, the the two first-order conditions of the firm's problem at $t=0$ determine $w_{i, 0}^{*}(i=h, l)$. Then, we are left with a system with five equations and five unknows. From proposition (1), given the equilibrium wages and university tuition, there exists an unique $a_{h}^{*} \in\left(\underline{a}_{h}, 1\right]$. From the law of motion (2), one obtains an unique $n_{h, 1}^{*} \in(0,1)$. As $n_{h, 1}^{*}+n_{l, 1}^{*}=1$, then there is an unique $n_{l, 1}^{*} \in(0,1)$. As in equilibrium $N_{i, 1}^{*}=n_{i, 1}^{*}$ (for $i=h, l$ ), then wages are uniquely determined using the firm's first-order conditions. Total number of students is equal to $\int_{a_{h}^{*}}^{1} f(a) d a$. Therefore, at the margin, the university with the highest marginal cost that has student is given by $i=X^{*}$ in the following equation: $\int_{a_{h}^{*}}^{1} f(a) d a=Q^{\max } \int_{0}^{X^{*}} i d i$. From the first-order condition of this university's problem (university $i=X^{*}$ ), $P^{*}$ is determined, as it equates price to its marginal cost. Universities with a marginal cost greater than $P^{*}$ do not operate as they maximize profits without having students. The proof is analogous to the case in which $a_{h}^{*}=1$.

Proposition 3: After the introduction of the program, if the university sector's supply curve is perfectly inelastic and the level of preparation of targeted students vis-à-vis the non-targeted ones is greater (lower), the quality of the labor force increases (decreases).

Proof. The following condition must hold in the competitive equilibrium with and without the government's program: 


$$
\beta \pi\left(a_{h}\right)\left[u\left(w_{h, 1}\right)-u\left(w_{l, 1}\right)\right]=u\left(w_{h, 0}\right)-u\left(w_{h, 0}-P\right)
$$

In the competitive equilibrium without the program, the above equality holds with the combination $a_{h}^{*}, w_{h, 1}^{*}, w_{l, 1}^{*}$, and $P^{*}$. When the program is introduced, there are $S$ new university students and, ceteris paribus, $P$ and $n_{h, 1}$ increases and the wage premium reduces, which leads to an increase in the RHS and a decrease in the LHS in the above equation. Hence, $a_{h}^{*}$ cannot be part of the competitive equilibrium anymore. To restore the equality in the above equation, $a_{h}$ has to increase (which affects $P, n_{h, 1}$ and the skill premium, reducing the $R H S$ and increasing the $L H S$ ) such that $S$ old students leave the university and the number of students enrolled in university does not change as the university sector's supply curve is perfectly inelastic. Let $a_{h}^{* *}$ be the new equilibrium threshold. After the program's introduction, the new $n_{h, 1}$ in equilibrium (call it $n_{h, 1}^{* *}$ ) is equal to:

$$
n_{h, 1}^{* *}=n_{h, 0}^{*} \int_{a_{h}^{* *}}^{1} \pi(a) f(a) d a+S \int_{a_{l}^{*}}^{\bar{a}_{l}} \pi(a) g(a) d a
$$

If the level of preparation of targeted students vis-à-vis the non-targeted ones is greater $\left(a_{h}^{*}<a_{l}^{*}\right)$ then $n_{h, 1}^{* *}>n_{h, 1}^{*}$. If it is lower $\left(a_{h}^{*}>\bar{a}_{l}\right)$, then $n_{h, 1}^{* *}<n_{h, 1}^{*}$.

Proposition 4: After the introduction of the program, if the university sector's supply curve is perfectly elastic, the quality of the labor force increases.

Proof. The following condition must hold in the competitive equilibrium with and without the government's program:

$$
\beta \pi\left(a_{h}\right)\left[u\left(w_{h, 1}\right)-u\left(w_{l, 1}\right)\right]=u\left(w_{h, 0}\right)-u\left(w_{h, 0}-P\right)
$$

In the competitive equilibrium without the program, the above equality holds with the combination $a_{h}^{*}, w_{h, 1}^{*}, w_{l, 1}^{*}$, and $P^{*}$. When the program is introduced, there are $S$ new university students and $P$ does not change as the university sector's supply curve is perfectly elastic. Ceteris paribus, $n_{h, 1}$ increases and the wage premium reduces, which leads to a decrease in the $L H S$ and an increase in the RHS in the above equation. Hence, $a_{h}^{*}$ cannot be part of the competitive equilibrium anymore. To restore the equality in the above equation, $a_{h}$ has to increase (which affects $n_{h, 1}$ and the skill premium, increasing the $L H S$ and decreasing the $R H S$ ). Let $a_{h}^{* *}$ and $n_{h}^{* *}$ be, respectively, the new equilibrium threshold and the new fraction of individuals with high level of human capital. As $a_{h}^{* *}>a_{h}^{*}$, then the new skill premium must be lower, indicating that $n_{h}^{* *}>n_{h}^{*}$ (that is, the quality of the labor force increases). 
Proposition 5: After the introduction of the program, if the university sector's supply curve is upward sloping and the level of preparation of targeted students vis-à-pis the non-targeted ones is greater (lower), the effect on the quality of the labor force is positive (uncertain).

Proof. The case in this proposition is a combination of the cases in the previous two propositions. Therefore, the proof is a straightforward convex combination of the previous proofs. 